Check for updates

Cite this as: $B M J 2020 ; 369: m 2331$ http://dx.doi.org/10.1136/bmj.m2331 Published: 12 June 2020

\section{Losing my licence meant I lost my independence}

Since the publication of this article by Zoe Barber (BMJ 2020;369:m1405, doi:), the DVLA has revised its guidance on driving after a seizure.

In light of evidence presented by the author to the Secretary of State's Medical Advisory Panel at the DVLA, the DVLA now considers eclampsia an exception in the provoked seizures category (, under the tab "show all updates").

This means women in the UK do not need to inform the DVLA or surrender their driving licences for six months following a confirmed diagnosis of eclampsia. 